

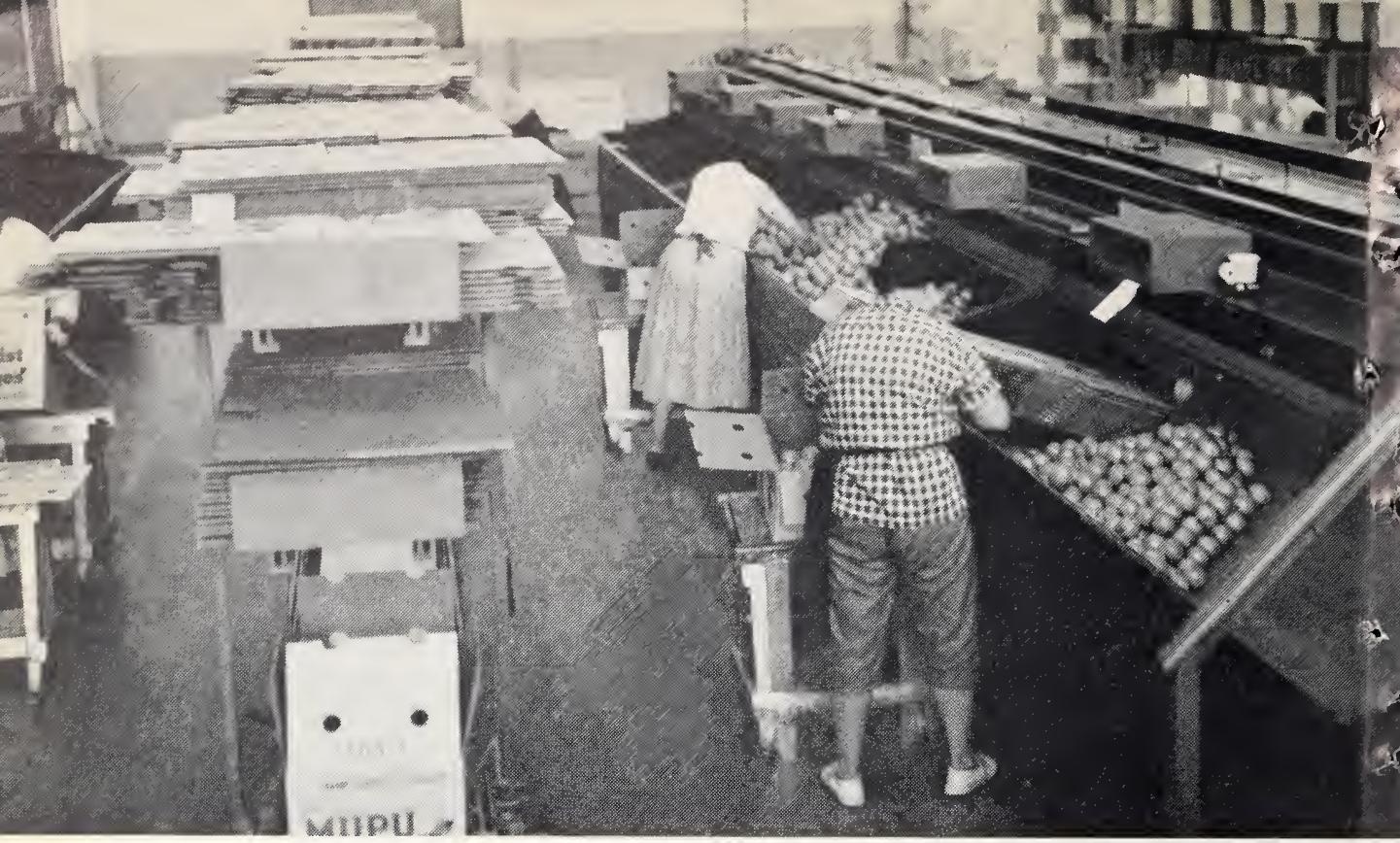

THE SIDE PACK OPERATION requires packers to turn sideways and stoop to pick up the fruitcontributes to excessive fatigue.

This circular describes a new and fast method of packing citrus fruit-a method which could very probably be applied to other fruits and to some vegetables.

Many of the operations and much of the machinery described here have been tried out and proved workable; some of the suggestions made are just that suggestions for further refinement of machinery and techniques.

The subjects discussed are as follows:

Special Requirements for Rapid Pack . . . . . . . . . . 5

Carton Forming for the Rapid Pack . . . . . . . . . . 9

Seating the Packers . . . . . . . . . . . 12

Training the Packers . . . . . . . . . . . . . . 14

Rapid Pack Bagging . . . . . . . . . . . . 16

\section{THE AUTHOR:}

Roy J. Smith is Professor of Agricultural Economics, Department of Horticultural Science; Agricultural Economist in the Agricultural Experiment Station and Citrus Research Center; Agricultural Economist on the Giannini Foundation. Riverside.

The drawings used in this circular were made or developed by Charles C. Papp. Scientific Illustrator in the Agricultural Experiment Station and Citrus Research Center. Riverside.

APRIL, 1963 


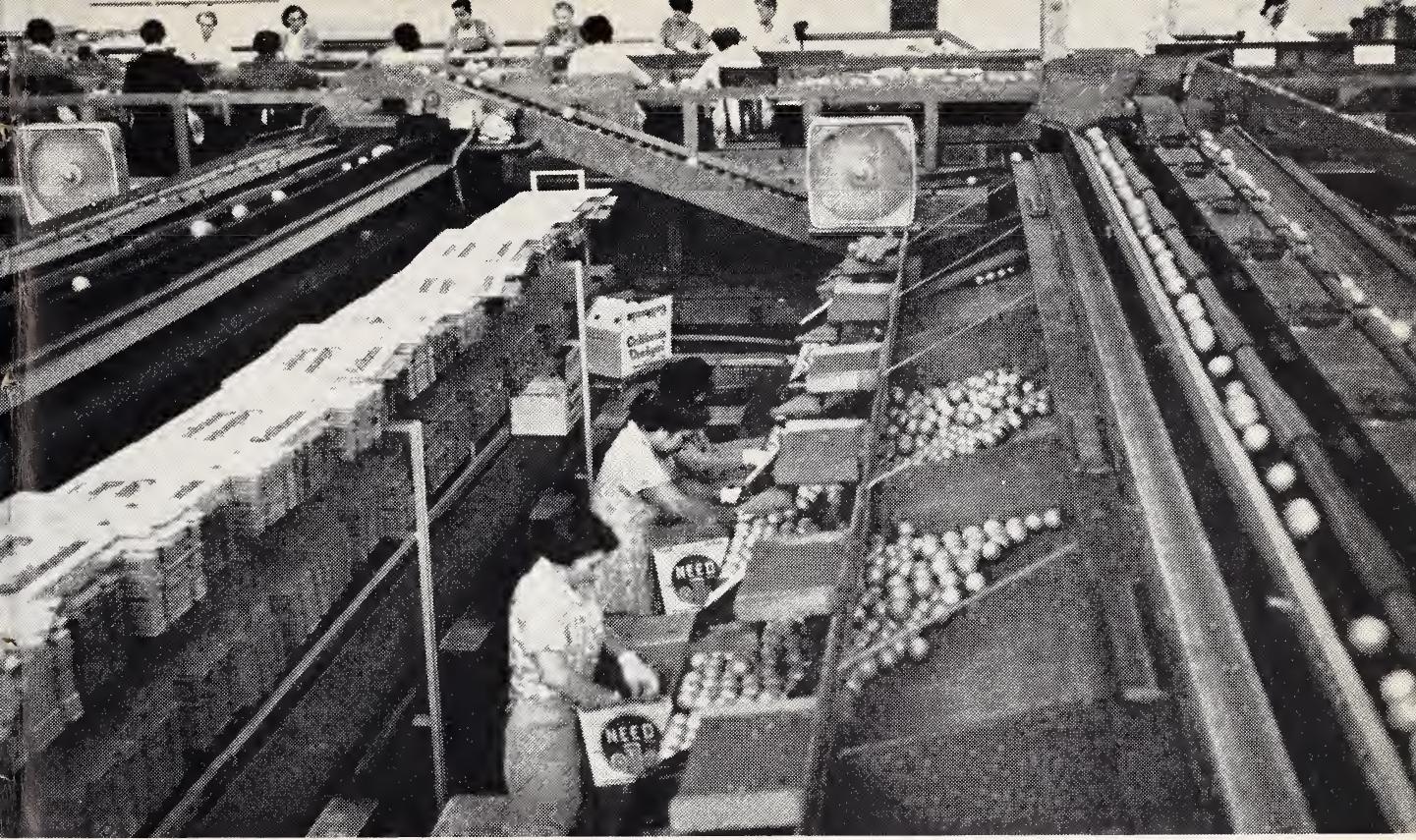

THE RAPID PACK METHOD has the packers working face-on; eliminates much of the turning and twisting-is conducive to greater speed.

THE RAPID PACK METHOD ...

\section{how it works}

THE pHotos above show the two basic methods of packing oranges now being used by packing houses. In the older. side pack method, the packer is obliged to lean twisted over the bin side as she reaches for fruit. In the newer, rapid pack method. the packer simply reaches forward across the rollboard, picks up the fruit and places it in the carton.

The rapid pack method is aimed at eliminating body bending and twisting, maintaining an erect posture, developing 
short, easy motions that will save time, and cut down on the strain and fatigue present under the side pack method.

The rapid pack method (or what purports to be the rapid pack method) has been observed in nine packing houses in California, two in Florida, and one in Australia. Other houses are converting to the system.

\section{Packing rates}

Table 1 presents some of the data obtained in several packing houses. Rates of pack range from 26.1 cartons per hour to 32.6 for the side pack and from 30.4 to $\mathbf{1 6 . 7}$ for the rapid pack. In all operations the rates have been adjusted from the actual average rates to an estimated one based on an average fruit size at 113 fruit per carton. The reduction in cost from rapid pack in House $A$, as compared with the side pack in other houses, approximates $2 \frac{1}{2}$ cents per carton. As compared with the other rapid pack houses, the reduction in cost in House $\mathrm{A}$ approximates $1 \frac{1}{2}$ cents.

The packers reported on in table 2 had all had at least 10 years of experience with the side pack prior to 1956 and had been using the rapid pack method since that time. The increases in rate of pack range from 28 per cent to 51 per cent and are for the entire season of worknearly six months' packing each. Every regular experienced packer in the house is included.

Some instalations have not resulted in any significant change in rate of pack. In one house (not recorded in the tables) there had been no increase in rate of pack. In still another house (not recorded) the packers would not use the rapid pack position but returned to the side pack and worked at about the same rate as from earlier bins. (See pages 6-7.)

\section{Worker fatigue and strain}

Strain is a very complex subject - it can result from many different actions such as twisting and stretching. Because of the more or less straight-line action required in the rapid pack system, twisting and stretching have largely been eliminated.

While fatigue cannot be eliminated entirely, the possibility of excessive tiredness in rapid pack houses has been watched for on numerous occasions and the conclusion is that there is no undue

Table 1. Comparison of rates of pack and cost per carton

\begin{tabular}{|c|c|c|c|c|c|c|}
\hline \multirow{2}{*}{ Packing house } & \multirow{2}{*}{ Variety } & \multirow{2}{*}{ Year } & \multicolumn{2}{|c|}{ Rate of pack } & \multirow{2}{*}{$\begin{array}{c}\text { Person } \\
\text { forming } \\
\text { carton }\end{array}$} & \multirow{2}{*}{$\begin{array}{l}\text { Cost of } \\
\text { packing }\end{array}$} \\
\hline & & & Side pack & Rapid pack & & \\
\hline & & & \multicolumn{2}{|c|}{ Cartons per hour } & & $\begin{array}{l}\text { Cents per } \\
\text { carton }\end{array}$ \\
\hline A. & Val & 1956 & 32.6 & & packer & 4.60 \\
\hline A. & Val & 1959 & $\ldots$ & 46.7 & packer & 3.21 \\
\hline A. & Val & 1960 & $\ldots$ & 46.5 & packer & 3.23 \\
\hline B. & Val & 1960 & $\ldots$ & 33.3 & former & 4.50 \\
\hline B. & $\mathrm{Nav}$ & 1960 & $\ldots$ & 32.9 & former & 4.56 \\
\hline $\mathrm{C} \ldots \ldots \ldots \ldots$ & Val & 1960 & $\ldots$ & 31.6 & packer & 4.75 \\
\hline c $\ldots \ldots \ldots \ldots$ & $\mathrm{Nav}$ & 1960 & $\ldots$ & 30.6 & packer & 4.90 \\
\hline D. & Val & 1960 & $\ldots$ & 30.4 & packer & 4.93 \\
\hline $\mathbf{E}$. & Val & 1960 & 27.6 & $\ldots$ & packer & 5.43 \\
\hline $\mathbf{F}$. & Val & 1960 & 26.1 & $\ldots$ & packer & 5.75 \\
\hline
\end{tabular}

These are seasonal average rates of pack in cartons per hour, per person in crew, including packers, special formers, and time of others distributing flats. Rate of pack has been adjusted to size of 113 fruit per carton. Costs of packing show seasonal average rates of pack per person in crew to return $\$ 1.50$ per hour to each crew member. 
Table 2. How rapid pack system increased rate of pack in House $A$

\begin{tabular}{|c|c|c|c|c|c|}
\hline \multirow{3}{*}{ Packer No. } & \multicolumn{3}{|c|}{ Rate of pack in cartons per hour } & \multicolumn{2}{|c|}{ Per cent increase over 1956} \\
\hline & \multirow{2}{*}{$\begin{array}{c}\text { Side pack } \\
1956\end{array}$} & \multicolumn{2}{|c|}{ Rapid pack } & \multirow{2}{*}{1959} & \multirow{2}{*}{1960} \\
\hline & & 1959 & 1960 & & \\
\hline$\ldots \ldots \ldots \ldots \ldots$ & 43 & 62 & 65 & 44 & 51 \\
\hline 2. & 36 & 46 & & 28 & \\
\hline 3. & 38 & 49 & 51 & 29 & 34 \\
\hline$\ldots \ldots$ & 35 & 47 & 50 & 34 & 43 \\
\hline
\end{tabular}

These were the experienced packers of House A. The figures are for their seasonal rates of pack in cartons per hour, adjusted to 113 count size.

fatigue. Packers themselves state that they are not so tired at the end of the day as they were using the side pack method. This lessening of fatigue is due to the natural, simple, short, hand, wrist, and arm movements made in the rapid pack system. No body motions are required, but if used, they are very simple. In fact, no significant physical effort is required other than that associated with speed. Under an incentive wage system the matter of speed is up to the packers' choosing between the extra effort required and the extra earnings to be obtained. If freedom is assured the packer to set the pace, there would appear to be no serious reason for concern as to fatigue.

Packers occasionally race each other, but proper management can usually prevent this. If packers think they will soon run out of fruit, they tend to overexert themselves while fruit is available. Thus fruit supply for all packers is an ex. tremely important factor.

\section{SPECIAL REQUIREMENTS}

\section{for the rapid pack method}

\section{Storage at packstands}

At best there is variation in the supply of fruit by sizes to the packstands but this variation can be materially modified if there is storage in bins at the packstands. Such storage has been standard for the side pack operations. However, if the old standard sizers with their bins are properly rebuilt for rapid pack, the storage space can be increased. Part of the increase can come from the rollboard and baffle systems, the designs for which are extremely exacting.

When converting standard sizer and bin units into a rollboard system for rapid pack operation, design the machinery to:

- Deliver to the rollboard edge a row or layer of fruit to be easily picked up.

- Allow individual fruits to roll through an empty bin to the rollboard edge, but never allow them to gain enough momentum to roll over the edge.

- Provide for as much storage space as possible.

The key to such storage is a baffle system which will hold back a pile of fruit and automatically allow a single layer of fruit to roll out. The drawing on page 6 shows such a baffle system.

\section{Maintaining correct posture}

Good posture for the packers is essential to the success of the rapid pack sys- 


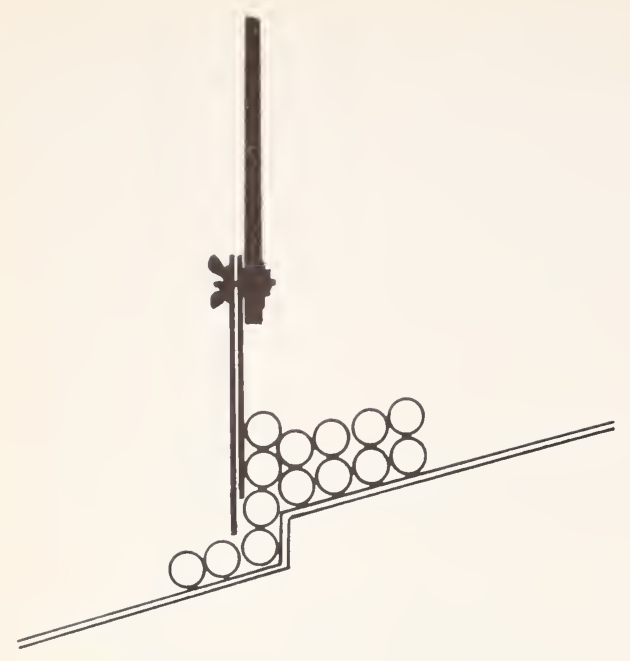

Baffle system for a rapid pack rollboard. Slope in floor is $3 \frac{1}{4}$ inches to a foot. The longer baffle slows individual fruits and prevents them from gaining a speed that will carry them over the edge. The two baffles together hold back the pile and allow only one layer to reach the rollboard edge. Wing nut allows adjustment. Drop in rollboard floor prevents fruit from wedging against the baffles.

tem. The system encourages good posture which, in turn, enables the packer to work faster without strain.

The rapid pack method is designed to keep the packers standing erect. Some tall packers may have to stoop a little to fill the bottom layer of a carton. In some installations it was noted that the cartons were placed much too low, causing the packers to stoop and resulting in strain. To avoid such conditions arrange the cartons so that:

- The packers' elbows will just swing clear of the carton edge when packer stands naturally.

- No stoop is required except a momentary one for very tall packers when filling the bottom row.

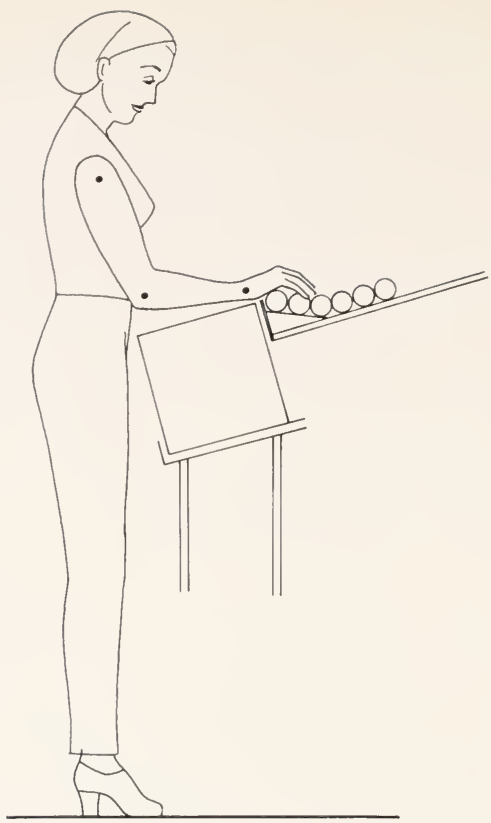

Posture and positioning of rollboard, carton, and fruit for rapid pack method. Rollboard edge and carton top are just 41 inches above the floor.

- The far edge of the carton and top front edge of the rollboard are together and at the same level.

- The rollboard edge is low enough so that the packers' forearms need not work at a slope greater than $15^{\circ}$.

These requirements leave little margin for variation. The rollboard edge must be about $41^{\prime \prime}$ above the floor and the near edge of the carton about 38". (See drawing above.)

Wrist alignment for packers is extremely important. When rollboard edges are too high packers must stretch their arms, wrists, and hands to reach the fruit and this results in a condition illustrated on page 7 .

In one packing house studied the rollboards were too high and the rate of pack was no faster than that for the side pack method. In fact the packers found it so difficult to reach the fruit they turned their boxes and resumed the position used in the side pack. 

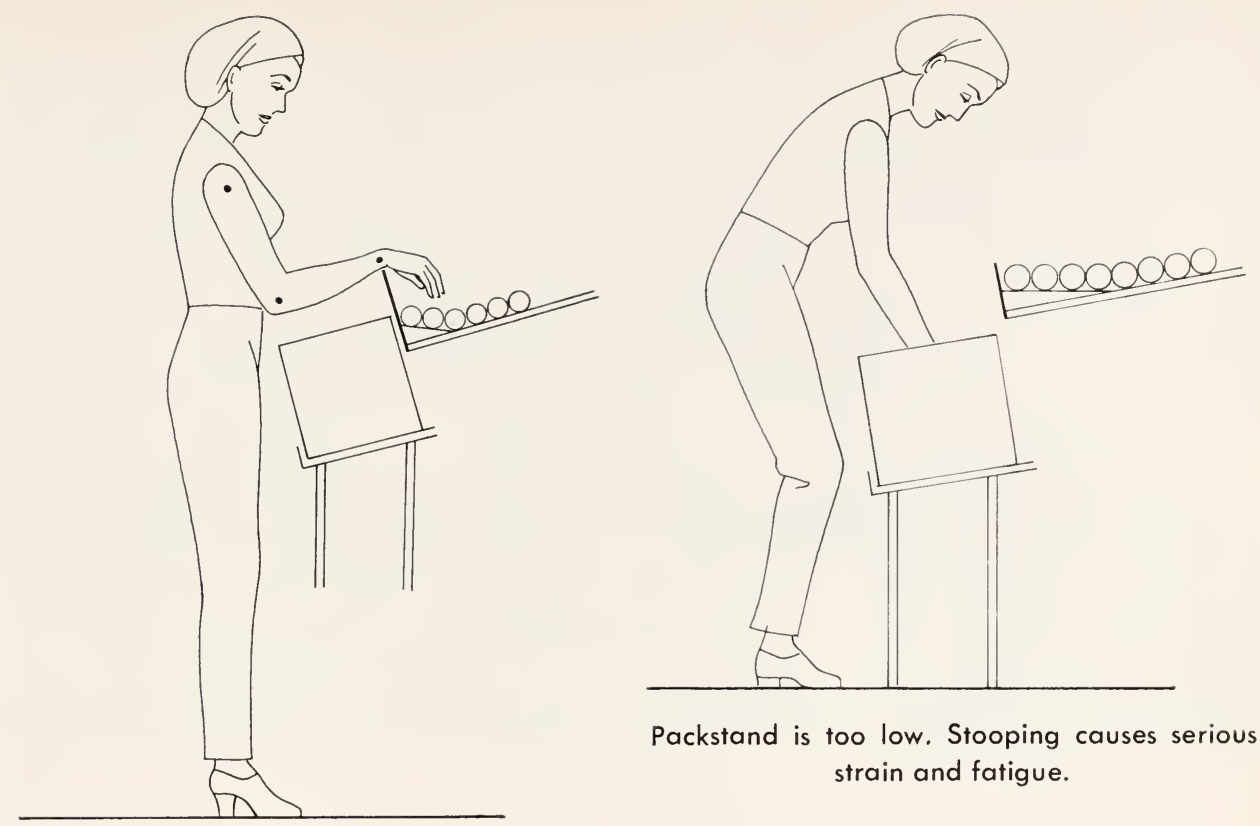

Packstand is too low. Stooping causes serious strain and fatigue.

High rollboard edge makes it difficult for packers to pick up fruit.

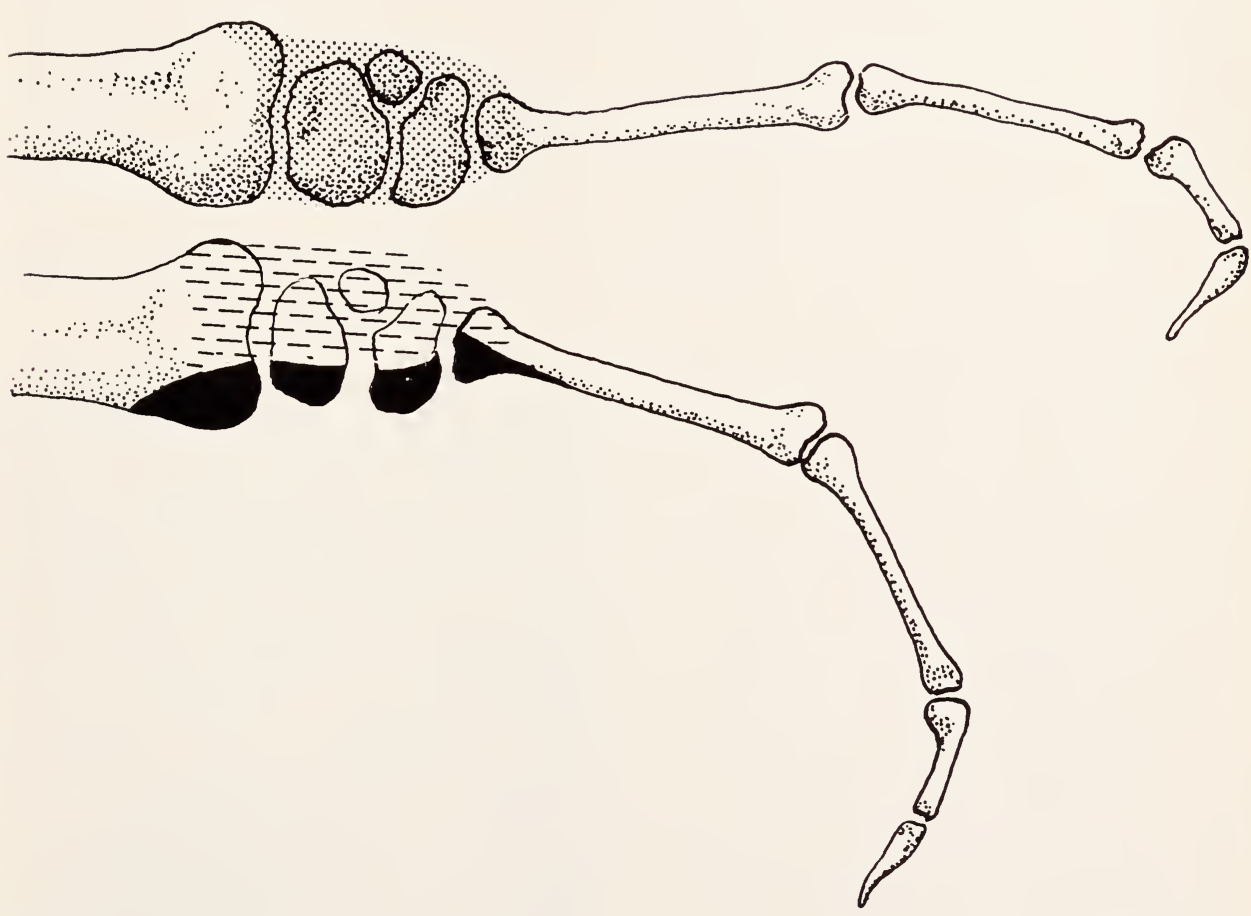

Sketch of wrist bones showing (top) normal position of the wrist, and (bottom) area where strain occurs when reaching over high fruit stop on the rollboard edge. 


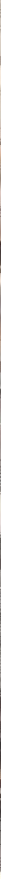

\section{Removing packed cartons}

The above picture of a rapid pack installation shows the most common equipment for removing packed cartons. Smoothed waxed boards are installed at intervals reaching from the packstand to a conveyor belt running behind the packers. A space is provided in each board for workers to pass. The packer can push her packed carton easily around back to the conveyor.

Careful design as to level is required so bottom flap edges will not catch. The conveyor belt should, if possible, be below the level of the packstand. Care must be taken also as to the number of such boards and the spacing between them; a packer should always have one at hand. on one side or the other, yet no more should be installed than are needed.

A second method of removing packed cartons is to install a conveyor belt below the rollboard, back of the packstand. The photo (right) shows such an installation. The complication with the system is placing the packstand so that it will be at just the right height for packing and yet allow space to move the packed carton back under the rollboard to the conveyor.
Proper packstand positioning requires that the edge of the carton next to the rollboard be at the same level as the rollboard top edge. In such an arrangement the rollboard edge prevents the carton from being pushed back onto the conveyor.

Consequently a mechanism must be provided for moving the carton. A trip mechanism might drop the packstand a few inches, thus allowing the carton to be pushed back. Such a trip mechanism appears simple but none has yet been seen.

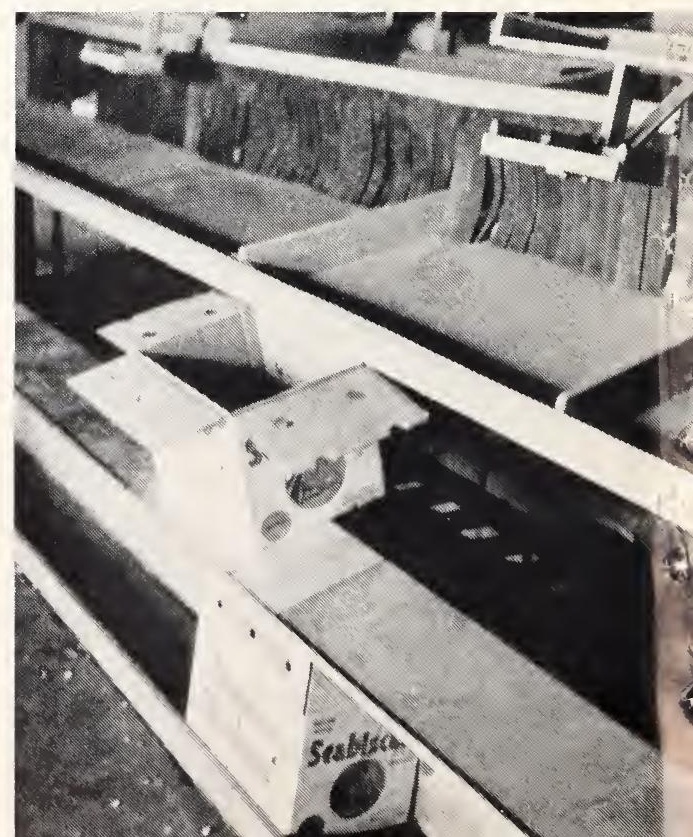




\section{Spacing of packers and supply of fruit}

It is recommended that a minimum of 3 feet per packer be allowed along the packstand. Materially lower rates of pack have been observed where there was crowding among packers but there is no reason to think that crowding had any bearing on the differences listed in table 1.

Where the supply of fruit fluctuates materially, crowding of packers around the peak sizes can limit the efficiency obtainable. A better distribution of fruit along the rollboard and among the packers would eliminate this problem.

There is no particular problem as to sizes, however - the problem is within a given size of fruit. If there is only enough fruit to keep one packer busy it should be sent to one position only (as is now usually done). The flow should be narrow enough so that the packer will not have to reach too far to one side.

Where there is enough fruit in a size for two or more packers, the fruit should be distributed in such a way that each packer has enough room and that only one end packer has the partial supply. (This assumes a "pack-around" system with each packstand position being taken in rotation to equalize the opportunity for maintaining rate of pack.)

It will be noticed in table 1 that House A packed fruit in 1956, under the old side pack, materially faster than the other houses using the side pack. This difference was almost entirely due to the constancy with which fruit was kept in front of the packers. It is normal to find packers in these other houses idle part of the time because of the fruit supply in the bins being low. This lack of fruit rarely happens at House A. The reasons for this difference are largely matters of management policy and apparently subject to control. The relationships involved are very complex. however, and will not be discussed here.

It should also be noted that House A has continued these policies as to supply of fruit with the Rapid Pack and they constitute one reason for the very high rate of pack that now obtains. In fact the policies are relatively more important under Rapid Pack than they are under the old pack.

\section{FORMING AND HANDLING CARTONS}

\section{for the rapid pack method}

While both House A and House B (table 1) used the rapid pack system of packing, the packers in House A formed their own cartons; those in House B had the cartons delivered to them already formed by someone else.

Both work-sampling and motion picture studies were made of these tasks in House A. A standard work time of 19 seconds was established for forming and handling. (In the studies the average time came out to 18.6 seconds but when some inexperienced people were included in the tests and some crowding occurred, the time went to 19.6 seconds.) A breakdown of the time required for the different tasks is shown in table 3.
The average packer takes 7.8 seconds to form her carton. This time includes reaching for the flats. She takes a total of 11.2 seconds to do the handling tasks. The rates of the very fast packer (table 3 ) indicate what perfection in motions will enable a worker to do. It may be noted that at another packing house (House D) packers appeared to have a more consistently good procedure in forming their cartons than those in House A. They were judged to be faster, although timing was not attempted.

An additional cost in time must be included for the distribution of flats in houses like House A. Since flats come in bunches, usually of 20 , constant attention 
Table 3. Time required for carton forming and handling

\begin{tabular}{|c|c|c|}
\hline Task & $\begin{array}{c}\text { Average } \\
\text { packer }\end{array}$ & $\begin{array}{l}\text { One very } \\
\text { fast packer }\end{array}$ \\
\hline \multirow{5}{*}{$\begin{array}{l}\text { Carton forming ....... } \\
\text { Fitting to packstand, } \\
\text { placing treated paper } \\
\text { After-packing tasks } \\
\quad \text { (stamping, etc.)..... }\end{array}$} & \multicolumn{2}{|c|}{ Seconds } \\
\hline & 7.8 & 6.4 \\
\hline & 2.2 & 2.2 \\
\hline & & \\
\hline & 9.0 & 7.7 \\
\hline TOTAL. & 19.0 & 16.3 \\
\hline
\end{tabular}

This table shows the total time required for carton forming and handling between the packing of two successive cartons. The overall time accuracy for the average packer rests on a work sampling coverage of a total of 2,551 cartons being packed under normal conditions. The breakdown in time and the rates for the very fast packer are based on motion picture studies. The study of the very fast packer did not include the addition of treated paper; time shown for her is assumed to be the same as for average packer.

is not required. The responsibility is usually assigned to one man, who, however, always has other responsibilities. Other people often gave the matter some attention. An exact study was not possible, but in House A with 2.000 cartons packed daily, it was estimated that a total of two hours was required. This calculates out to 3.6 seconds per carton. Adding this time to the standard time of 19 seconds for forming and handling ly the packer gives a total carton forming and handling time of 22.6 seconds. The figure, $3.6 \mathrm{sec}$ onds, is included in the total time requirement per carton (table 1) for houses where packers form their own cartons.

Time required by "formers" in House $B$ was established from the incentive wage records. Over a full season the time per carton averaged 13.8 seconds. This time was for forming cartons, sometimes the inserting of treated paper, and pushing the cartons down the chute.

The men who formed cartons in House $B$ were capable of considerable speed. They averaged 10.1 seconds per carton for one 11-hour week. 10.6 seconds for one 3t-hour week. and 10.8 seconds for one 39.5-hour week. Even then, however, their time never equalled that of average packers at House A, which was $7.8 \mathrm{sec}$ onds per carton. The forming at House B was in the chute: pushing it could take only a moment, even though it required some strength. When treated paper was added. it also required but a moment.

The synchronization of formers with the needs of packers is very difficult. Much of the time the formers could not be kept busy. The number of cartons required per week varied from 2,169 to 13,154. During one week the rate of forming dropped to 20.2 seconds per carton, simply because the packing was slow.

At any given time. synchronization of forming and packing is difficult. A solid line of packers can empty a full chute of formed cartons in about two minutes. The former must maintain an exceptional zeal if a full supply of formed cartons is to be maintained for all packers.

Enough formers must be on hand to take care of peak packing demands and the incentive rate per carton must be high enough to attract formers during times of low demand. Thus costs cannot be kept as low as when forming is a minor task of the total packing job.

A further difficulty with forming cartons beforehand is that when formed cartons are squeezed tightly in the chute they are often difficult to get out. In many instances the bottom flaps come loose and more time is taken to fold them in again than was needed to put them in originally.

A further generalization but a very pertinent one is that the interval between the packing of two cartons, when used to form a new carton. constitutes a complete change in motion for the packer and. as such, provides a moment of relaxation. This interval of change is quite in contrast to the task of the specialized former who does one simple task over and over. 
Supply of carton flats. Where the cartons are formed by the packers, observations have shown that efficiency can be gained in supplying flats by:

- Keeping the level of the feed line as low as possible to prevent the strain of reaching. (This may require lowering the level of the packed carton conveyor, then lowering the feed line to a point where it just clears the top flaps of the cartons on the conveyor.)

- Setting bunches of flats on the feed lines in such a way that they can be pulled out and formed without having to be turned around. Usually this is done by having the flaps pointed toward the packers.
- Keeping a watchful eye on the feed lines to make sure they are fully supplied at all times.

Forming motions. Certain specific procedures can be suggested for efficient forming of cartons by packers.

- The packstand. the point where the packed cartons are disposed of, the supply of carton flats, and the place for forming should be close together.

- There must be a fixed, solid place for forming the carton.

- The two carton halves can be fitted together best by fitting the bottom half into flaps of top-or by fitting flaps of top half over the bottom half.

\section{BACK BOARD}

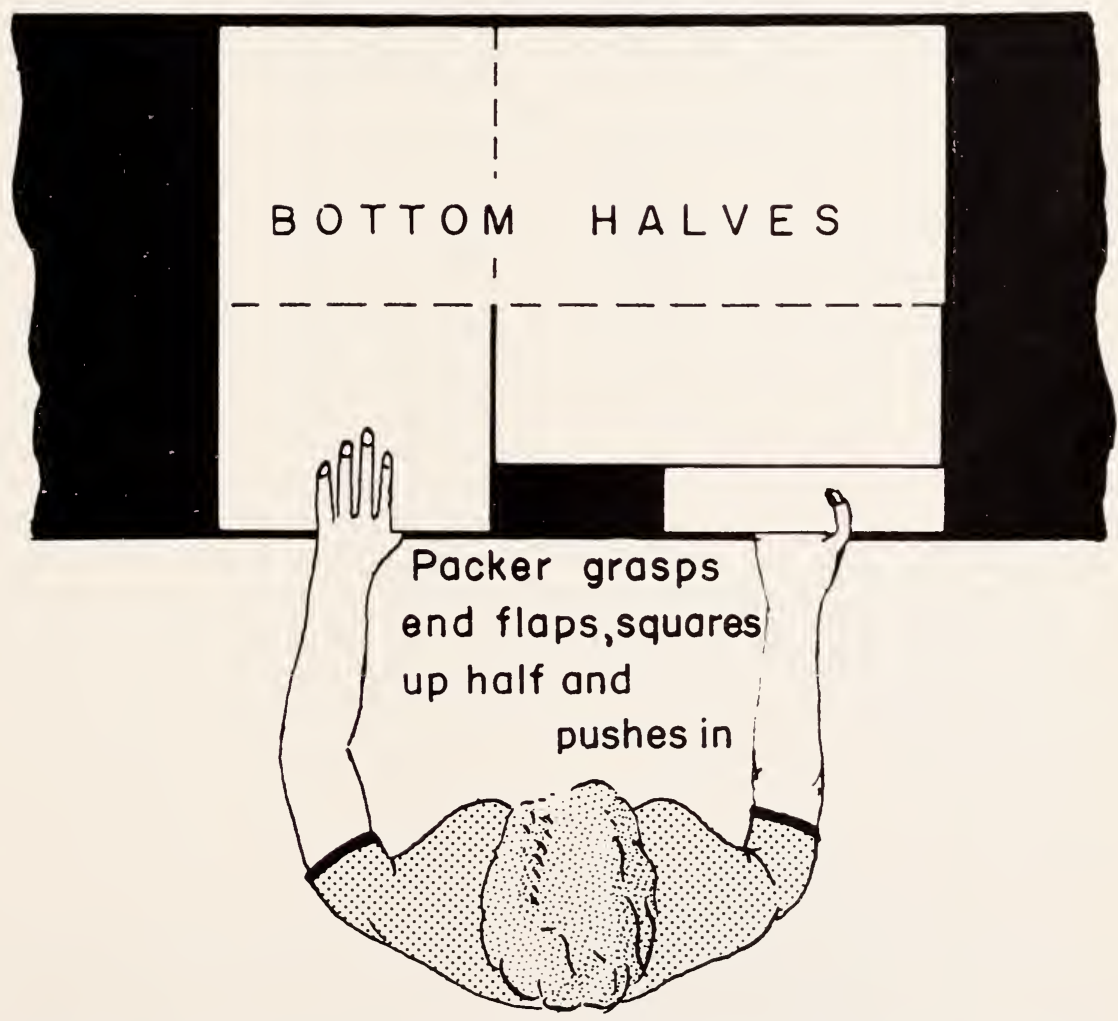

Packer in third sequence grasps ends of bottom flaps, squares them up and forms the half-all in one motion. 
Any of the following sequences may be used hy packers working standing up, and able to turn around easily:

1. Pull out the bottom half by the ends of the end flaps; square the carton; place carton butt-end down on the solid surface; fold (push down) in the end flaps (already being held in hands) : fold in side flaps, all in one smooth motion. Pull out top half; square it; fit its flaps down over the bottom half in a second single smooth motion. The whole is then turned over, pushed together, and fitted to the packstand. Or,

2. Pull out the top half by its end flaps; square it and set it in the packstand. Pull out bottom half by end flaps; square it: set it down on a solid place and push in flaps. Slide hands to corner of the formed half, turn it over and set it down between flaps of top half; push it to the bottom and fit whole to packstand. Or,

3. A third sequence is proposed and may be used if a space of about 22 inches in height can be provided above the bundle of bottom halves so that these halves can be formed right there. The packer then squares up the bottom half (see drawing) by grasping ends of end flaps and twisting with hands. As half is squared, end flaps can be pushed in almost in the same motion; push in side flaps and slide hands to corner of the formed half and grasp it. Turn with formed half and set it down into flaps of top half (as in 2nd sequence).

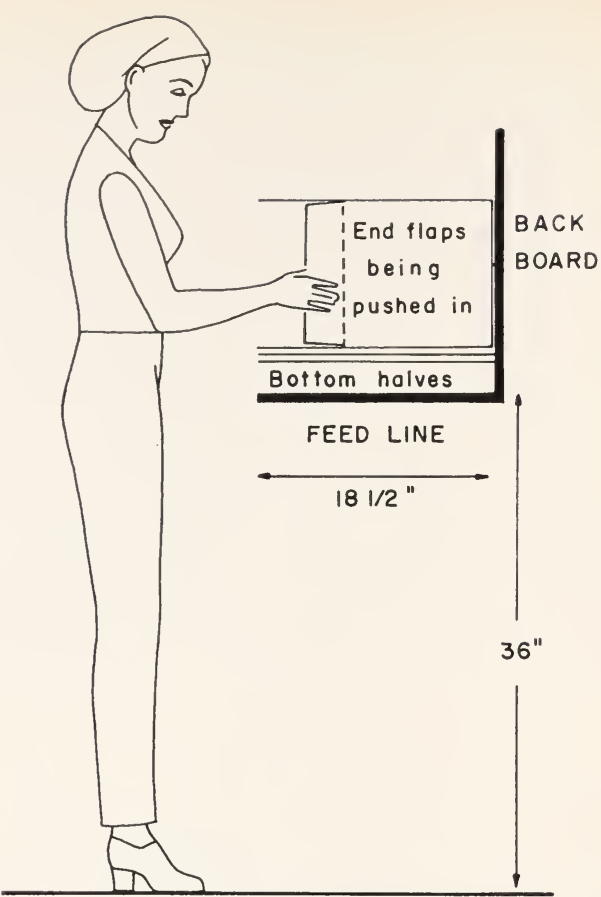

To use third sequence, bottom halves must be at right height so packer can use weight to push in flaps.

This 3rd sequence differs from the 2 nd in that height of feed chute for bottom halves must be close to 36 inches, otherwise packer cannot use her weight when pushing flaps; there must be a backboard against which packer pushes to form flaps. But no other "place" is needed for forming bottom halves, and the packer saves time of setting down the bottom halves to form them, and then picking them up again.

\section{SEATING THE PACKERS}

\section{requires adjustments in equipment}

The possibility of seating packers has been tested several times and the idea has both advantages and disadvantages. The packers found they could work just as fast seated as when standing and. of course preferred to work seated as it was less tiresome. It is common to find graders who had to give up packing because of the strain of standing all day so it is possible that if seating can be 
the packers can use them while seated but push them out of the way when standing. Also, taller and shorter packers might have to take their foot rests with them when moving to different stations in the pack-around system because all of the seats would he at a standard height.

Forming cartons while seated presents some problems. Delivery of the flats involves using two conveyors-one for tops and another for bottoms-or alternating bundles of tops and hottoms on one conveyor. The latter system would require less room but would demand very close attention from the person

\section{TRAINING THE PACKERS}

\section{will pay off in efficiency}

There is considerable difference in the rate of pack among packers and undoubtedly some of this difference is in the temperament and native ability of the individuals. But there are also differences that are due to faulty ways of doing things-ways that can be changed or never allowed to develop if packers are correctly trained in their work.

This is especially true if the training can be given to new packers-it will be difficult to break bad habits of long standing in experienced packers. keeping the feed lines supplied. The flats must be arranged so they reach the packers with the butts of the bottom halves and the top flaps of the top halves facing out.

A suggested sequence for forming cartons while seated is: Pull out bottom flaps: turn butt of carton down and drop onto packstand; square carton; push flaps down and in.

Pull out top half by flaps; square up carton: turn flaps down and fit over bottom half. Turn whole carton over; fold top and side flaps back as carton is fitted into packstand.

While some training might be desirable in the tasks of forming cartons. stamping. use of treated paper, and recording the pack, most of these routine procedures will be learned quickly by the packers from watching those alongside.

The various pack patterns take a few days to learn, but two weeks' experience seems to be sufficient to make these al. most automatic.

Picking up fruit is one of the difficulties of inexperienced packers. Training might help here.

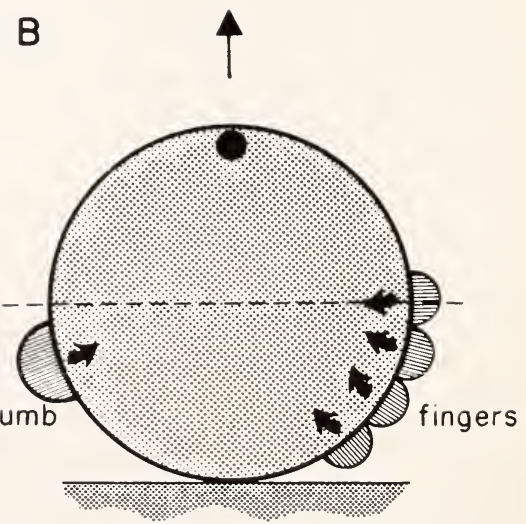

Contrast in methods of picking up fruit; $A$ - with all fingers above middle of fruit, and $\mathrm{B}-$ with fingers below. 
Some packers have the ability to pick up two fruits in one hand and this gives them an advantage in speed over others. Practice can be important in learning to pick up two easily.

A flat, tight layer of fruit can be difficult to pick up; the fingers do not easily reach under the fruit and occasionally fingers have become sore from pushing between the fruits.

The drawing on page 14 shows two commonly used methods of picking up fruit-the pressure grasp (A) and the full hook grasp. In the pressure grasp all fingers and the thumb are above the largest circumference of the fruit and pressure must be exerted to prevent the fruit from slipping out of the hand. In the full hook grasp fingers and thumb are on the lower part of the fruit and no pressure is required to hold it. Obviously, the full hook method is less tiring. Two measures can be suggested to help. The rollboard recommended (see drawings below) has a "riser" at the edge and the floor of the rollboard is flattened for

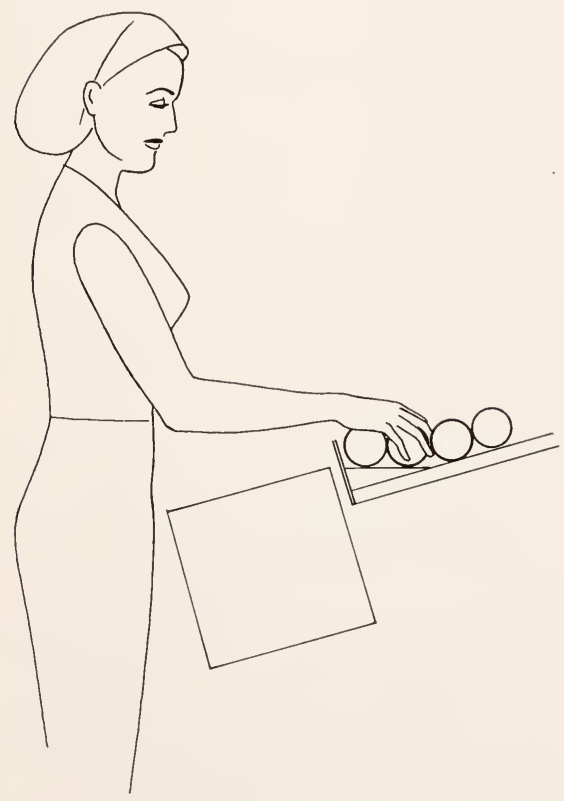

about four inches to reduce the pressure on the first row of fruit behind. This feature, together with the low fruit stop, or rollboard edge, makes it possible to pick up the first row of fruit quite easily. The second measure is to have beginners watch experienced packers and see how they fit their fingers around the fruits. It is not simply a matter of pushing but of watching for spaces between fruit and of fitting fingers into these spaces. Alertness in eye and practice in finding these spaces can help a great deal.

Arm motions. Observations have shown that usually one of four different arm motions is used; two hands in unison, one hand alone, hands alternating, or an arm sweep. Using two hands in unison is undoubtedly the fastest method, but a variation in arm methods is recommended to reduce fatigue.

The use of one hand alone should be avoided except when it is necessary to use the other hand to hold fruit in position to build a pattern in the carton. The alternating motion is very fast at times,

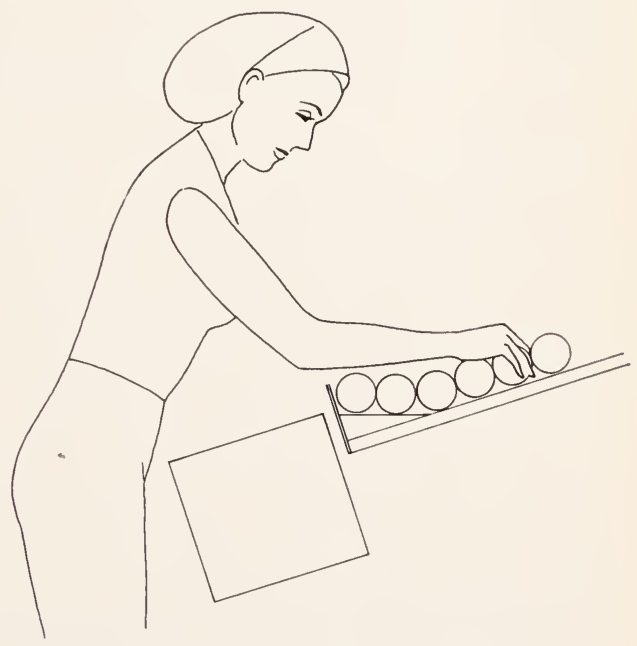

Left-how packer should get her fingers between fruits in a solid layer. Above, leaning over the fruit is an unnecessary exertion and can be avoided. 


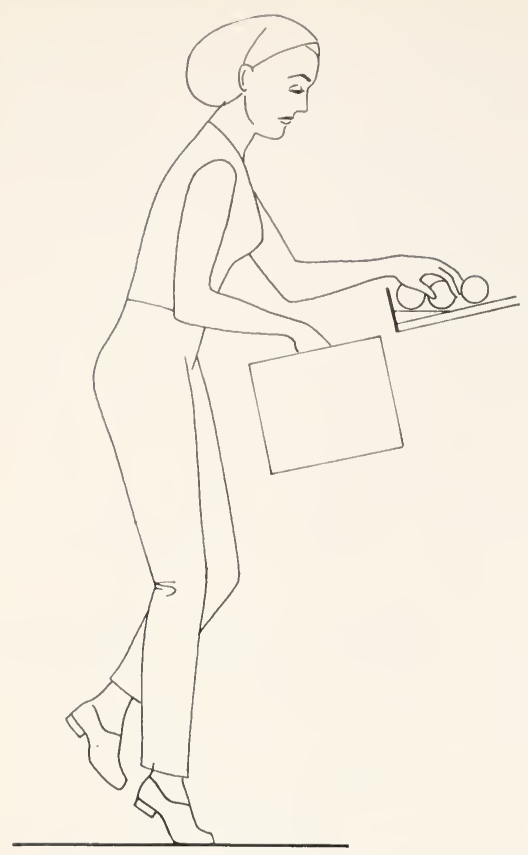

Standing on one leg is awkward and leads to fatigue. Tall women should wear flat heels and short women should wear elevator shoes. but usually results in only one fruit being picked up at a time whereas using two hands in unison seems to make it more practical to pick up two fruits in each hand.

In the arm sweep method the packer simply leans over and encircles a dozen or so fruit with her arm, then sweeps them over the edge into the box. While fast, this method tempts the packer not to arrange the fruit in the desired pattern and may also lead to damaged fruit. Some packing houses prohibit the practice. Its proper use seems to depend on supervision by management and a sense of responsibility by the packers.

Posture. A prime purpose of the rapid pack system is to enable the packers to stand or sit erect while working, and thus reduce strain and fatigue. Drawings on pages 15 and 16 show two bad habits followed by packers. While bad posture habits may be extremely difficult to break in the more experienced packers. management (and workers) would both benefit greatly by training new packers in good posture.

\section{RAPID PACK BAGGING}

\section{has worked well in trials}

Mechanical equipment for bagging lras long been available and considered satisfactory for large-scale operations working over long periods of time. but where the use of bags is intermittent or on a small scale, the operation has usually been performed by hand. Doing the job by hand has been slow and inefficient.

The following are suggestions for machinery and procedures that could be adapted to the rapid pack rollboard equipment for small-scale bagging of many kinds of fruit when desired. The recommendations made are based on trials with experimental machinery, none of which is currently available commercially.
Rapid pack bagging equipment may be used in conjunction with a rapid pack rollboard. The fruit on the rollboard is at a convenient height for efficient operation and can be rolled down through a slot, directly into the bag. The equipment needed is not expensive, but its design is quite specific. (See drawing page 17.)

The drawings on page 18 show the sequence of motions for bagging fruit. The packers can maintain a comfortable posture and stretching is reduced to a minimum.

The empty bags are laid in bundles on the machine board. A new bag is always at fingertips, ready to be opened and fitted over the bag mouth holder. It need only be moved about 3 inches. 


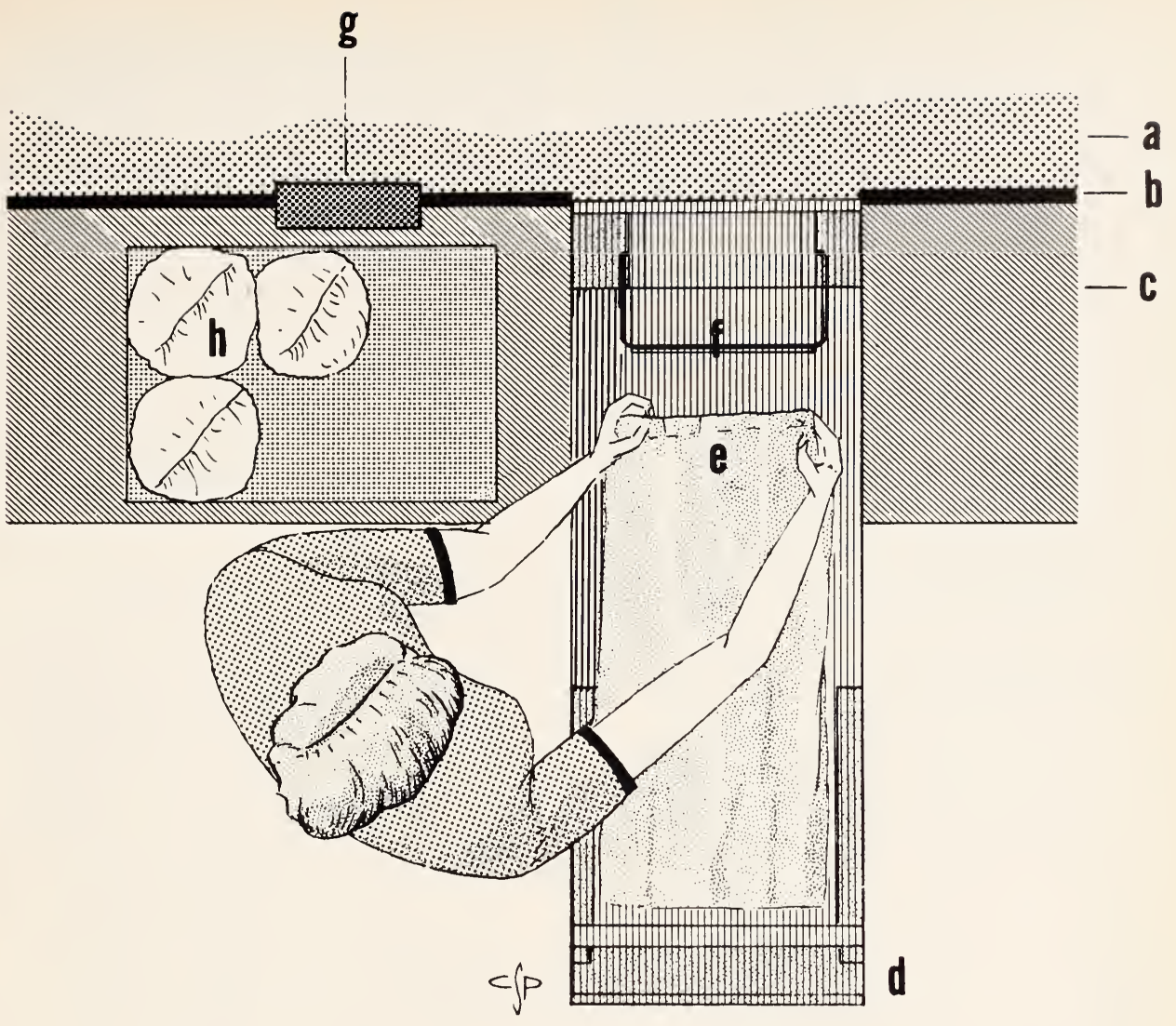

Plan view of bagging equipment. A-rollboard of rapid pack equipment; B-rollboard edge with opening at $\mathrm{F} ; \mathrm{C}$-packstand; $\mathrm{D}$-bag holding machine; $\mathrm{E}$-bag ready to be fitted over gate; $\mathrm{F}$-gate or bag mouth holder; $\mathrm{G}$-sealing equipment; $\mathrm{H}$-bagged fruit in container. The bag holding machine was designed and built by Haruo Najima, former Assistant Specialist in the Agricultural Experiment Station, Los Angeles.

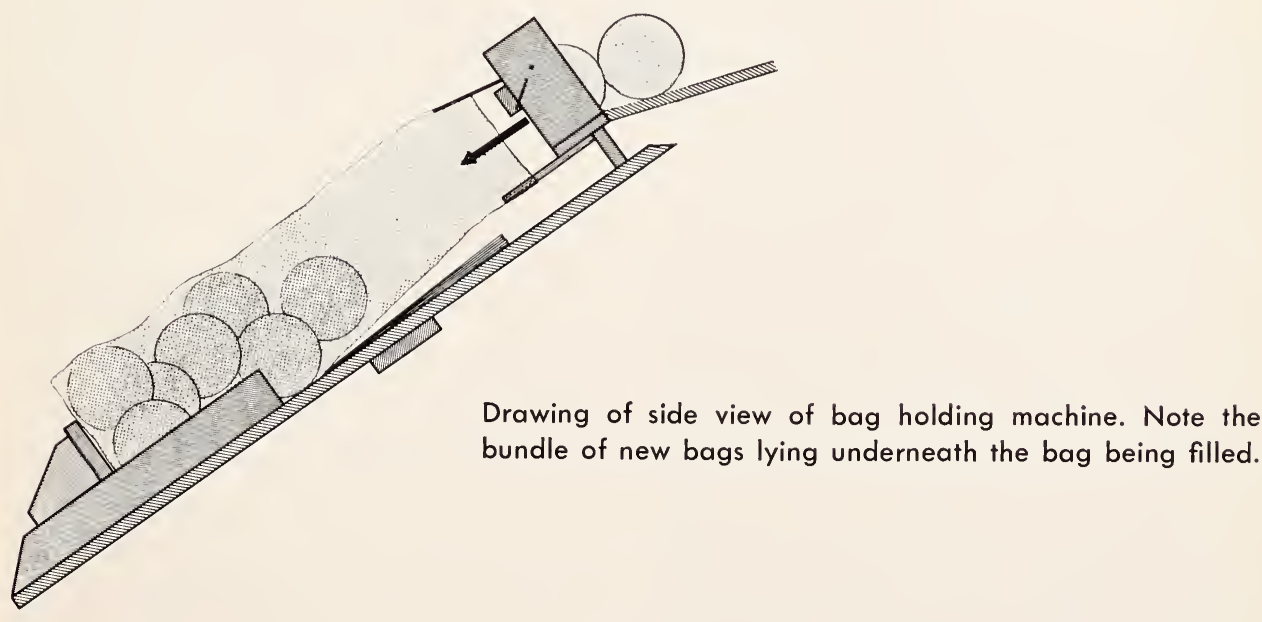



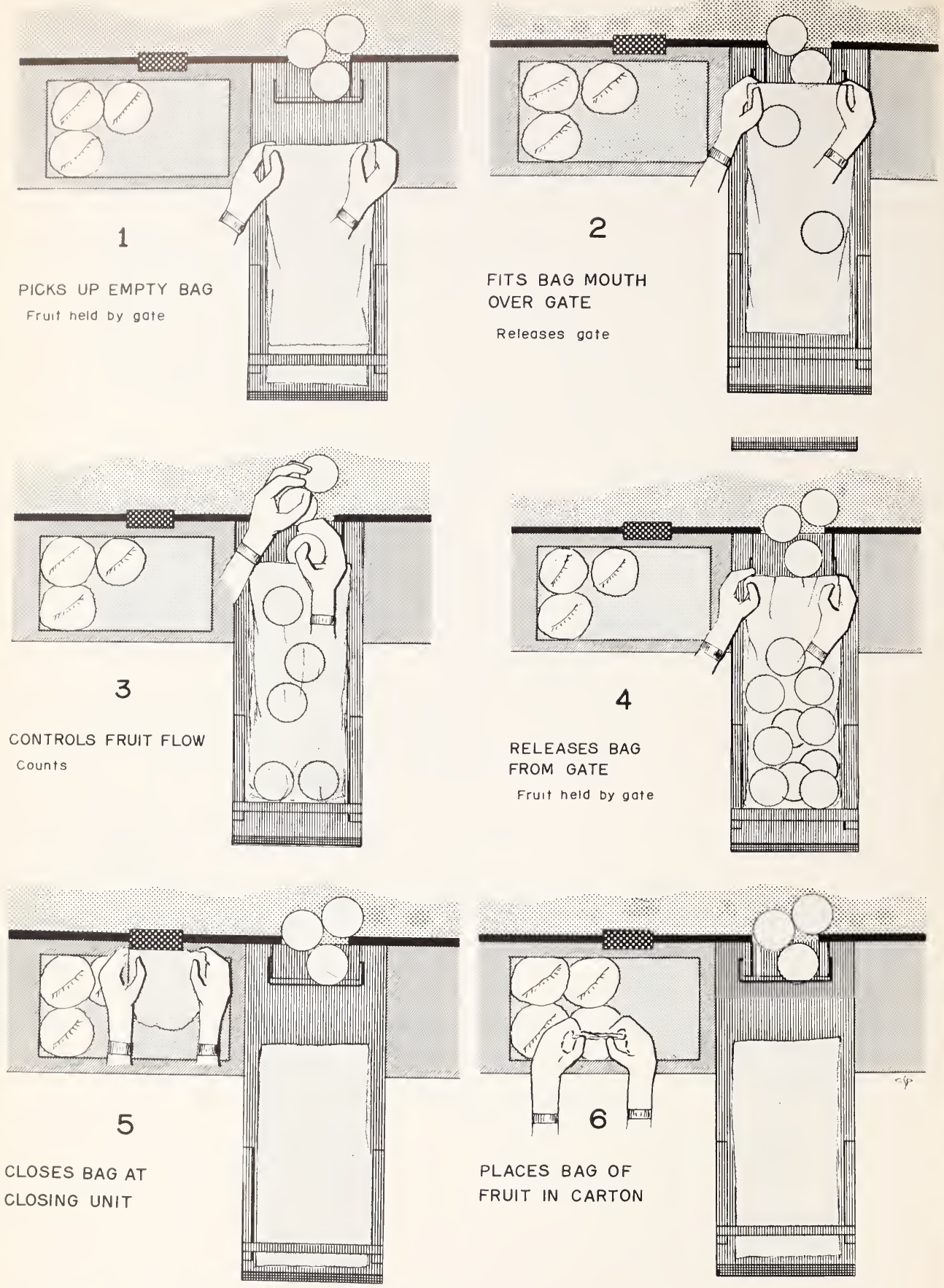

Sequence of motion activities in bagging fruit. 


\section{Design and manufacture}

As stated, the equipment proposed here will require a degree of exactness in design. A different size hag holder will be required for each bag size and since various manufacturers offer bags in different dimensions and materials it would seem desirable that each build his own gate and bag mouth holder. These could be sold or leased as an adjunct to the sale of bags. The same might apply to closing units.

\section{Bagging at wholesale or retail}

Where the operation is of sufficient size, the machinery and procedures outlined here could be adapted to wholesale or even retail locations that could provide a rollboard or circulating belt. If fruit is shipped in bulk bins, the bins could be emptied directly onto the rollboard. 